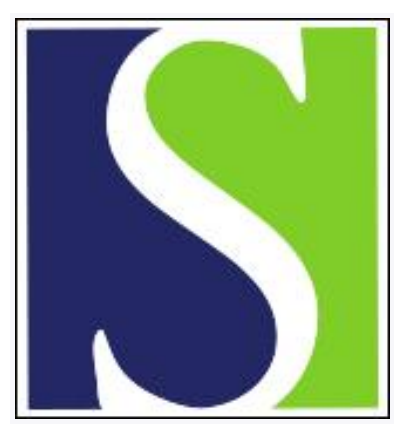

Scand J Work Environ Health 2000;26(5):382-389

https://doi.org/10.5271/sjweh.558

Issue date: Oct 2000

Impact of occupation on respiratory disease

by Nathell L, Malmberg P, Lundbäck B, Nygren $\AA$

Key terms: agriculture; food industry; health economics; long-term sick leave; metal worker; occupational asthma; painter; secondary prevention; sick leave

This article in PubMed: www.ncbi.nlm.nih.gov/pubmed/11103836

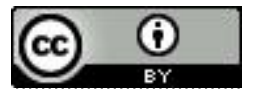




\title{
Impact of occupation on respiratory disease
}

\author{
by Lennart Nathell, MD, 1,2,3 Per Malmberg, MD, ,2,3 Bo Lundbäck, MD, ${ }^{3,4}$ Åke Nygren, $M D^{2}$
}

\author{
Nathell L, Malmberg $\mathrm{P}$, Lundbäck B, Nygren $\AA$. Impact of occupation on respiratory disease. Scand $J$ Work \\ Environ Health 2000;26(5):382-389.
}

\begin{abstract}
Objectives This study identified occupations with a marked impact on sick leaves due to respiratory disease. Methods A national sick-leave register containing information on all sick leaves exceeding 14 days, physicians' diagnoses, and the occupational status of all manual and service employees in the private sector in Sweden was studied. Sick leaves during 1992-1994 (N=210 755) were analyzed with special attention to respiratory disease and occupation.

Results Respiratory disease accounted for $4.4 \%$ of the total number of sick leaves. The incidence of long-term ( $\geq 90$ days) sick leaves due to respiratory disease was 3 times higher in occupations with a high incidence than in those with a low incidence. There was a high correlation $(r=0.80)$ between the incidence of long-term sick leave due to respiratory disease and sick leave due to all other conditions; this finding suggests that market and selection factors may play an important role in determining the overall risk for sick leave in various occupations. The proportion of sick leaves due to long-term respiratory disease out of all long-term disease was compared between occupations. Agricultural workers had a $46 \%$ higher proportion of long-term respiratory disease than metal workers. Industrial workers, food industry workers, and painters were also occupations with an increased risk. These findings could not be explained by differences in age or smoking habits.

Conclusions Major differences were found among manual and service occupations regarding long-term sick leave due to respiratory disease. Several occupations, in which exposure to respiratory sensitizers and irritants are known to occur, were among those in which workers had an increased risk for long-term respiratory disease.
\end{abstract}

Key terms agriculture, food industry, health economics, long-term sick leave, metal workers, occupational asthma, painters, secondary prevention, sick leave.

Epidemiologic research over the last 30 years has increased knowledge on occupational lung disease. The relationship between occupation and respiratory disease can be viewed from different aspects. First, a certain type of occupation or exposure can cause a respiratory disease. Second, irritant exposure in the workplace can aggravate preexisting lung disease or induce symptoms. Third, physical demands at the workplace can prevent or hinder persons with an existing respiratory disease from doing any type or certain types of work. Finally, social behavior, such as tobacco smoking, that affects lung function can differ between occupations (1).

In many countries there are national surveillance systems for work-related disease. These systems record persons identified by physicians as having an occupational disease and reflect diagnostic tradition and incentives to report such cases, which can vary over time and between countries. The SWORD project in Britain (2) and the SENSOR system in the United States (3) are such examples. Sweden (4) and Finland (5) have similar surveillance systems.

In Sweden, however, there is another type of register, one that lends itself to the study of the total impact of occupation on respiratory, or other, illnesses, rather than the impact on the incidence of occupational lung disease. It is the national sick listing register for compulsory sickness insurance [Avtalsgruppsjukförsäkringen (AGS) in Swedish]. Each sick leave exceeding 14 days is recorded together with the physician's diagnosis. The physician's diagnosis states the disease, but no opinion about its work-relatedness, and such a diagnosis is required for all periods of sick leave exceeding 14 days.

The aim of the present study was to investigate the impact of occupation on sick leave due to respiratory

1 The Åre Clinic, Åre, Sweden.

2 Section of Personal Injury Prevention, Department of Clinical Neuroscience, Karolinska Institutet, Stockholm, Sweden. 3 National Institute for Working Life, Stockholm, Sweden.

4 Olin Study Group, Department of Medicine, Central Hospital of Norrbotten, Boden-Luleå, Sweden.

Requests for reprints: Lennart Nathell, The Åre Clinic, Kurortsvägen 20, SE-830 13 Åre, Sweden. [E-mail: lennart.nathell@cns.ki.se] 
disease. Both long-term ( $\geq 90$ days) and short-term sick leaves (14-89 days) due to respiratory disease were studied and compared with all other causes of sick leave. A study of the impact of age and gender on sick leave was also included, and the analysis was focused on longterm disease. Since the AGS register does not provide information on the size or age and gender distribution of the population from which the cases were recruited, data from a labor force survey made in 1993 were analyzed. These data were compared with data from union registers on the rate of union enrollment.

\section{Materials and methods}

\section{Study population - the AGS register}

AGS is a compulsory national insurance system regulated by a collective agreement between all members of the Swedish Labor Union Confederation and the Swedish Employers' Confederation. The employers pay for this insurance, and it covers 2.5 million employees in Sweden, mainly manual and service workers, regardless of membership in a labor union. The insurance partly compensates for loss of income during sick leave. During the study period (1992-1994) persons on sick leave for more than 14 days were compensated for loss of income for up to the 90 th day. The number of days compensated for each sick leave is registered together with the diagnosis, gender, age, residential area, name of employer, and occupation (labor union).

The diagnoses are taken from certificates of illness issued by physicians. A modified version of the coding system used in the International Classification of Diseases is used to enter the diagnosis in the AGS register. The term used in the register for respiratory diagnoses and respiratory symptoms is "respiratory diseases". The term "respiratory diseases" includes diagnoses and symptoms such as acute respiratory tract infections, asthma, bronchitis, emphysema, chronic obstructive pulmonary disease (COPD), allergies, cough, and dyspnea. Tumors in the respiratory tract and specific respiratory tract infections such as tuberculosis have separate terms and are not coded under "respiratory diseases".

For the present study, the 3-year period from January 1992 to December 1994 was chosen. Manual and service occupations in the Swedish private sector were included. Public employees and mariners were not included because of disparities in agreement and compensation terms. Occupations with less than 10000 workers (musicians, miners, and sheet-metal workers) were also excluded. The group "industrial workers" is comprised of workers in various sectors, for example, industries such as textile, garment, leather, chemical, rubber, plastics, oil-refining, glass, porcelain, gas, pharmaceutical, sugar, laundry, and stone, cement, concrete and other building material.

The exact number of insured persons in each occupation is not known. An estimate was obtained from data from the labor force surveys of 1993, based on 189000 observations [Personal communication from the National Census Bureau, Statistics Sweden (labor force surveys in Sweden 1993), 13 March 2000]. The National Census Bureau performs this yearly survey. Information on gender, median age together with quartiles, and proportion of union members 60 years and older, was obtained for those who had stated union membership. Information on the rate of enrollment in each labor union in 1993 was obtained from the various labor unions. The number of workers in each occupation was calculated by dividing the estimated number of members in each labor union by the rate of enrollment for every labor union. According to the labor force surveys, 849000 persons were registered as members in the included labor unions. The average rate of enrollment in a labor union was $84 \%$. Thus the calculated number of insured persons in the studied material was 1.0 million employees, constituting $27 \%$ of the total Swedish work force (table 1). Hence the study base comprised persons employed with manual and service occupations in the private sector during the period January 1992 to December 1994, approximately 3.0 million person-years. Information on the diagnosis, occupation, age, and gender of persons on sick leave was obtained from the AGS register.

The correctness of the certificates of illness issued with a respiratory diagnosis was validated by a postal questionnaire to a random sample of 800 , out of 9245 , issuing physicians. The main question in this questionnaire was whether the stated diagnosis in retrospect was certain, nearly certain, or uncertain. A random subsample of 6000 sick leaves, out of 210755 , was studied regarding the registration of diagnoses to determine the exact diagnosis and frequency of misclassification.

\section{Methods and analysis}

The data were analyzed using SPSS (Statistical Products and Service Solutions) for Windows, release 10.0.5.

All sick leaves exceeding 14 days, starting between 1 January 1992 and 31 December 1994, were included in the analyses. The analyses comprised sick leaves due to respiratory disease and sick leaves due to all other causes, "nonrespiratory disease".

Short-term sick leave was defined as a sick leave lasting between 15 and 89 days. Long-term sick leave was defined as a sick leave lasting 90 days or longer. Age was defined as the age at the start of sick leave.

The $95 \%$ confidence intervals $(95 \% \mathrm{CI})$ were calculated using the mean values plus and minus 1.96 times the standard error. For the binomial proportions $p$ in 
the different samples of size $n$, the standard error was calculated using the formula $\sqrt{(p(1-p) / n)}$.

Multiple logistic regression models were used to describe the relationship between the dependent dichotomous variable sick leave and the independent variables gender, age, and occupation. In the study of the influence of occupation in these models, use was made of the deviation contrast method whereby each category of occupation, except the reference category, was compared with the overall effect. Metal workers were chosen as the reference category since they made up more than $25 \%$ of the material and therefore contributed the most to the overall effect.

\section{Results}

Altogether 210755 sick leaves lasting more than 14 days were registered during 1992-1994 among the manual and service employees included in the study. This value corresponds to an estimated incidence of 70 sick leaves per 1000 workers and year. The most common reasons for sick leave were musculoskeletal disorders, which constituted $59.3 \%$ of the total number of registered periods. Respiratory diseases accounted for $4.4 \%$ of the total number of sick leaves ( 9245 sick leaves). Respiratory diseases accounted for $9.0 \%$ of the sick leaves lasting $15-$ 28 days, for $3.3 \%$ of those lasting $29-89$ days, and $2.9 \%$ of those lasting $\geq 90$ days. The women had a higher proportion of sick leaves due to respiratory diseases than the men, $4.9 \%(95 \% \mathrm{CI} 4.7-5.0)$ of all registered sick leaves compared with $4.1 \%$ (95\% CI $4.0-4.2$ ) for the men. More than 1 sick-leave period due to respiratory disease during the study period was registered for $8.9 \%(95 \% \mathrm{CI}$ $8.1-9.7)$ of the men and $12.7 \%(95 \%$ CI 11.6-13.8) of the women.

The most common registered respiratory diagnoses were respiratory tract infections (including bronchitis) $(67.8 \%)$, asthma $(13.0 \%)$, allergic symptoms from the respiratory tract $(2.5 \%)$, respiratory symptoms (cough, dyspnea, chest tightness, etc) $(1.6 \%)$, pleurisy (1.3\%), and pneumothorax $(1.2 \%)$. The response rate to the validation questionnaire to the issuing physicians (without a reminder) was $91 \%$. The physicians reported in retrospect that $94 \%$ of the stated diagnoses were certain or nearly certain. In the study of misclassification errors $(\mathrm{N}=6000)$, the number of respiratory sick leaves incorrectly registered as nonrespiratory periods was 48 , and the number of nonrespiratory sick leaves incorrectly registered as respiratory periods was 40 .

The estimated incidence of long-term ( $\geq 90$ days) sick leaves due to respiratory disease ranged between 0.4 and 1.2 per 1000 workers and year for different occupations. Incidences of long-term sick leave exceeding 0.9 per 1000 worker-years were found for food industry workers, woodworkers, industrial workers, and caretakers (table 1). There was, however, a strong correlation ( $r=0.80)$ between the estimated incidences of long-term respiratory sick leave and long-term nonrespiratory sick leave (figure 1a).

Similarly, the proportion of sick leaves due to respiratory disease, compared with those due to other causes,

Table 1. Estimated number of workers, median age, gender, and yearly incidence per 1000 person-years of long-term ( $\geq 90$ days) sick leave due to respiratory disease. $(95 \% \mathrm{Cl}=95 \%$ confidence interval)

\begin{tabular}{|c|c|c|c|c|c|c|c|c|}
\hline \multirow[t]{3}{*}{ Labor union } & \multirow{3}{*}{$\begin{array}{l}\text { Estimated } \\
\text { number } \\
\text { of workers } \\
\text { (thousands) }\end{array}$} & \multicolumn{3}{|c|}{$\begin{array}{c}\text { Age } \\
\text { (years) }\end{array}$} & \multirow{3}{*}{$\begin{array}{l}\text { Aged } \\
60 \text { years } \\
\text { or older } \\
(\%)\end{array}$} & \multirow[t]{3}{*}{$\begin{array}{l}\text { Men } \\
(\%)\end{array}$} & \multirow{2}{*}{\multicolumn{2}{|c|}{$\begin{array}{c}\text { Yearly incidence per } \\
1000 \text { person-years of } \\
\text { long-term respiratory } \\
\text { sick leave }\end{array}$}} \\
\hline & & \multirow[t]{2}{*}{ Median } & \multicolumn{2}{|c|}{ Quartiles } & & & & \\
\hline & & & 1 st & 4th & & & Incidence & $95 \% \mathrm{Cl}$ \\
\hline Food industry workers & 41.8 & 34 & 25 & 46 & 2.9 & 62 & 1.2 & $0.8-1.5$ \\
\hline Wood workers & 41.8 & 37 & 28 & 49 & 5.4 & 81 & 1.1 & $0.8-1.5$ \\
\hline Industrial workers & 73.4 & 37 & 30 & 48 & 4.0 & 63 & 1.1 & $0.9-1.4$ \\
\hline Caretakers & 35.2 & 37 & 28 & 49 & 4.6 & 57 & 1.0 & $0.7-1.3$ \\
\hline Graphic printers & 35.8 & 41 & 29 & 50 & 5.3 & 68 & 0.9 & $0.6-1.2$ \\
\hline Papermill workers & 27.4 & 38 & 28 & 47 & 3.2 & 85 & 0.9 & $0.5-1.3$ \\
\hline Metal workers & 268.1 & 37 & 27 & 48 & 2.8 & 80 & 0.9 & $0.8-1.0$ \\
\hline Forestry workers & 10.3 & 43 & 30 & 50 & 3.7 & 92 & 0.8 & $0.3-1.4$ \\
\hline Transportation workers & 59.4 & 35 & 27 & 46 & 2.2 & 85 & 0.8 & $0.6-1.0$ \\
\hline Agricultural workers & 14.9 & 32 & 25 & 43 & 3.7 & 63 & 0.8 & $0.3-1.2$ \\
\hline Painters & 15.9 & 32 & 23 & 43 & 2.8 & 98 & 0.8 & $0.3-1.2$ \\
\hline Construction workers & 96.1 & 33 & 26 & 46 & 2.7 & 99 & 0.6 & $0.4-0.7$ \\
\hline Commercial workers & 222.1 & 37 & 26 & 49 & 5.0 & 28 & 0.5 & $0.4-0.6$ \\
\hline Hotel \& restaurant workers & 44.2 & 29 & 23 & 40 & 2.5 & 31 & 0.4 & $0.2-0.6$ \\
\hline Electricians & 21.9 & 33 & 25 & 44 & 4.7 & 99 & 0.4 & $0.1-0.7$ \\
\hline Total & 1008 & & . & . & 3.6 & 68 & 0.8 & $0.7-0.8$ \\
\hline
\end{tabular}


a)

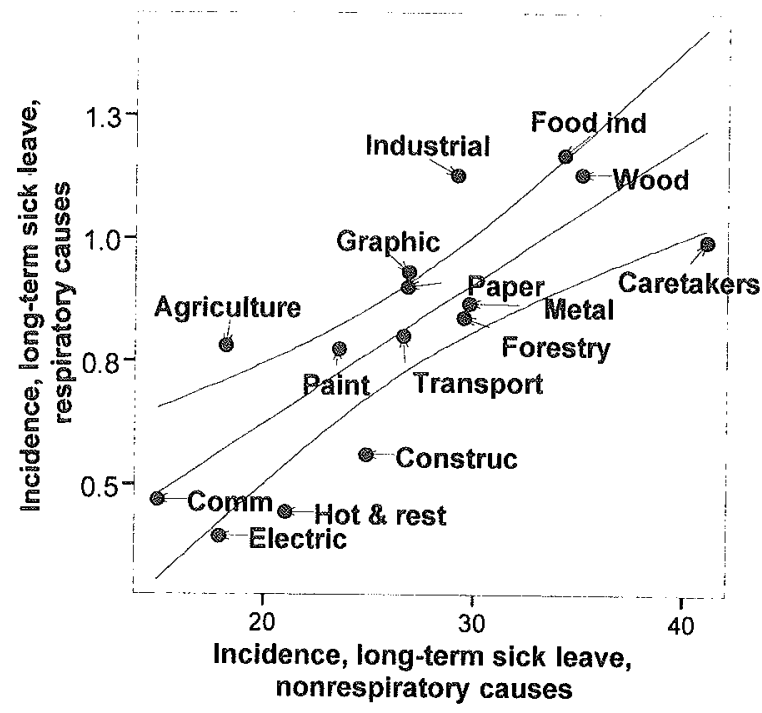

c)

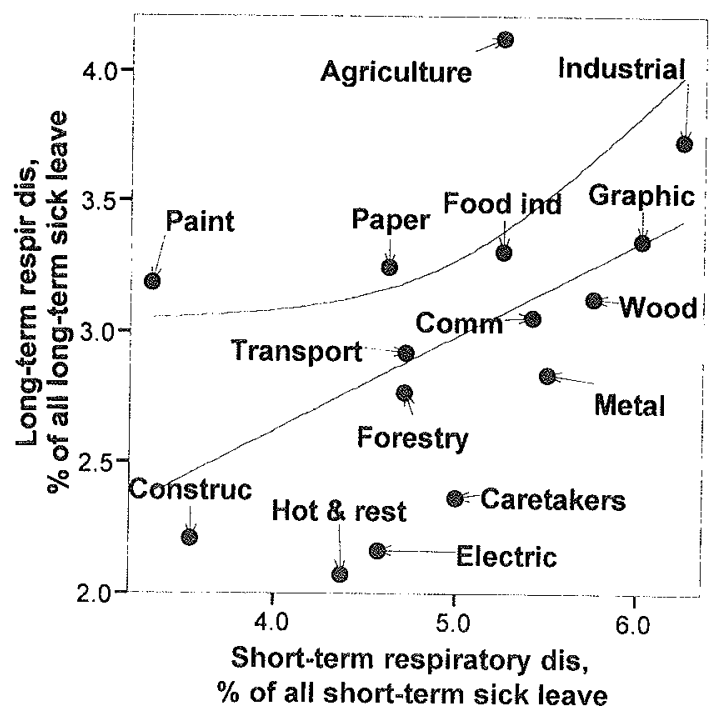

b)

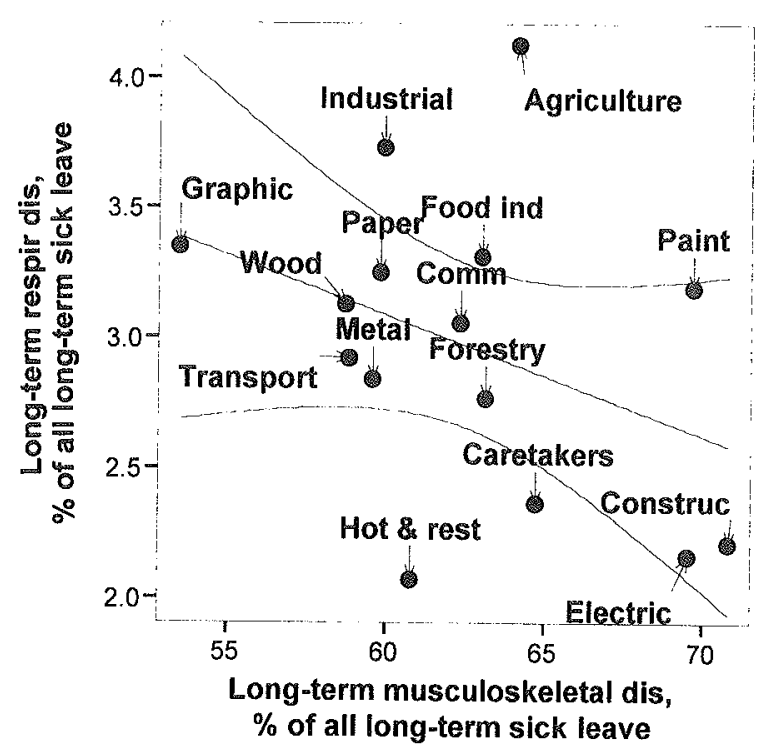

d)

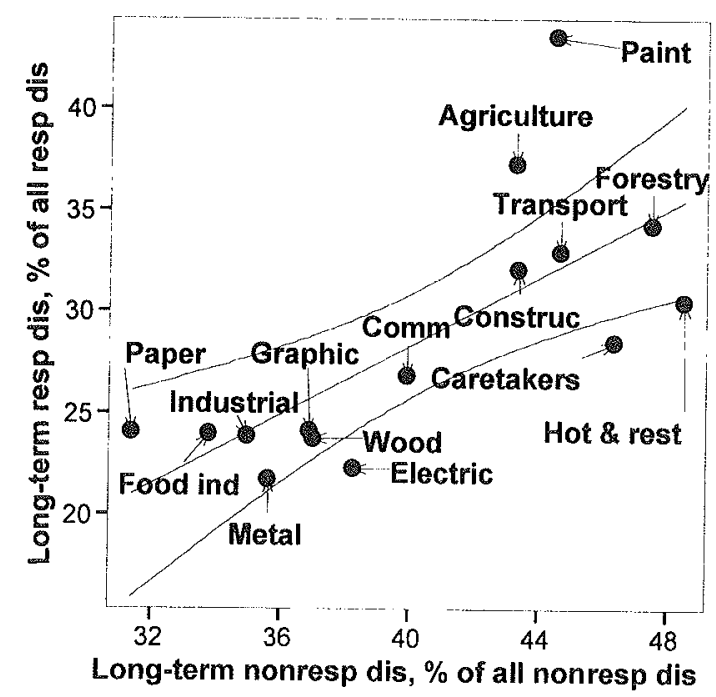

Figure 1. Scatter plots with the predicted regression line and $95 \%$ confidence intervals for relations between incidences of long-term sick leave with respiratory and nonrespiratory causes (a), proportions of long-term respiratory sick leave (out of all long-term sick leaves) and long-term sick leave due to musculoskeletal disease (out of all long-term sick leave) (b), proportions of long-term respiratory disease (of all long-term disease) and short-term respiratory disease (out of all short-term disease) (c), and proportions of long-term respiratory disease (out of all respiratory diseases) and long-term nonrespiratory diseases (out of all nonrespiratory disease) (d). (resp \& respir = respiratory, nonrespir = nonrespiratory, dis $=$ disease, Construc $=$ construction, Comm $=$ commercial, Hot \& rest $=$ hotel \& restaurant, ind $=$ industry)

differed markedly between occupations (table 2). Thus $4.1 \%$ of all the long-term sick leaves among agricultural workers had a respiratory diagnosis compared with $2.2 \%$ of the sick leaves among electricians, who had the same age distribution (table 2).

In occupations with an increased proportion of longterm sick leaves due to musculoskeletal diseases, the proportion of respiratory diseases as a cause of long-term sick leave tended to decrease $(r=-0.37)$. Persons employed in agriculture and industrial workers had relatively higher proportions of long-term sick leaves due to respiratory disease (figure $1 \mathrm{~b}$ ).

There was a correlation between the proportions of long and short-term sick leaves with respiratory causes (out of all long- and short-term sick leaves) for different occupations ( $\mathrm{r}=0.50$ ) (figure $1 \mathrm{c}$ ). Painters and agricultural workers deviated, however, from the regression and showed an excess of long-term sick leaves in relation to short-term periods. In contrast, caretakers, electricians, and persons employed in hotels and restaurants tended 
to have relatively more shorter periods of sick leave due to respiratory disease.

In occupations in which a high proportion of workers with respiratory disease had long-term sick leaves (compared with those with short-term sick leaves) (table 3), there was also a tendency towards a high proportion of long-term sick leaves among those with other

Table 2. Proportions of sick leaves due to respiratory disease out of all sick leaves and all long-term sick leaves. $(95 \% \mathrm{Cl}=$ $95 \%$ conifdence interval)

\begin{tabular}{lcccc}
\hline $\begin{array}{l}\text { Occupational } \\
\text { group }\end{array}$ & $\begin{array}{c}\text { Proportion of } \\
\text { respiratory sick } \\
\text { leaves out of } \\
\text { all sick leaves }\end{array}$ & $\begin{array}{c}\text { Proportion of } \\
\text { respiratory long- } \\
\text { term sick leaves } \\
\text { out of all long- } \\
\text { term sick leaves }\end{array}$ \\
\cline { 2 - 3 } \cline { 6 - 7 } & Proportion & $95 \%$ Cl & Proportion & $95 \% \mathrm{Cl}$ \\
\hline Agricultural workers & 4.8 & $3.8-5.7$ & 4.1 & $2.8-5.5$ \\
Industrial workers & 5.4 & $5.1-5.7$ & 3.7 & $3.3-4.2$ \\
Graphic printers & 5.0 & $4.6-5.5$ & 3.4 & $2.7-4.0$ \\
Food industry workers & 4.6 & $4.2-5.0$ & 3.3 & $2.8-3.8$ \\
Papermill workers & 4.2 & $3.7-4.7$ & 3.2 & $2.5-4.0$ \\
Painters & 3.3 & $2.6-3.9$ & 3.2 & $2.2-4.2$ \\
Woodworkers & 4.8 & $4.4-5.2$ & 3.1 & $2.6-3.6$ \\
Commercial workers & 4.5 & $4.2-4.7$ & 3.1 & $2.7-3.4$ \\
Transportation workers & 3.9 & $3.6-4.3$ & 2.9 & $2.5-3.4$ \\
Metal workers & 4.6 & $4.4-4.7$ & 2.8 & $2.6-3.0$ \\
Forestry workers & 3.8 & $3.0-4.6$ & 2.8 & $1.7-3.8$ \\
Caretakers & 3.8 & $3.4-4.2$ & 2.4 & $1.9-2.8$ \\
Construction workers & 3.0 & $2.7-3.2$ & 2.2 & $1.9-2.5$ \\
Electricians & 3.7 & $3.0-4.3$ & 2.2 & $1.3-3.0$ \\
Hotel and restaurant workers & 3.3 & $2.8-3.7$ & 2.1 & $1.6-2.6$ \\
\hline Total & 4.4 & $4.3-4.5$ & 2.9 & $2.8-3.0$ \\
\hline
\end{tabular}

Table 3. Proportions of long-term sick leaves out of of all sick leaves due to respiratory disease. $(95 \% \mathrm{Cl}=95 \%$ confidence interval)

\begin{tabular}{|c|c|c|}
\hline \multirow[t]{2}{*}{$\begin{array}{l}\text { Occupational } \\
\text { group }\end{array}$} & \multicolumn{2}{|c|}{$\begin{array}{c}\text { Proportion of long-term sick } \\
\text { leaves out of all respiratory } \\
\text { sick leaves }\end{array}$} \\
\hline & Proportion & $95 \% \mathrm{Cl}$ \\
\hline Painters & 43.5 & $33.0-54.1$ \\
\hline Agricultural workers & 37.2 & $27.5-47.0$ \\
\hline Forestry workers & 34.2 & $23.5-44.9$ \\
\hline Transportation workers & 32.9 & $28.5-37.3$ \\
\hline Construction workers & 32.0 & $28.0-36.1$ \\
\hline Hotel and restaurant workers & 30.4 & $23.9-36.9$ \\
\hline Caretakers & 28.5 & $23.9-33.1$ \\
\hline Commercial workers & 26.8 & $24.2-29.3$ \\
\hline Graphic printers & 24.0 & $19.9-28.1$ \\
\hline Papermill workers & 24.0 & $19.3-28.8$ \\
\hline Food industry workers & 23.9 & $20.6-27.3$ \\
\hline Industrial workers & 23.8 & $21.2-26.4$ \\
\hline Woodworkers & 23.7 & $20.3-27.1$ \\
\hline Electricians & 22.2 & $14.7-29.8$ \\
\hline Metal workers & 21.7 & $20.3-23.1$ \\
\hline Total & 25.1 & $24.2-25.9$ \\
\hline
\end{tabular}

diseases $(r=0.72)$ (figure 1d). Painters and agricultural workers deviated and had higher than expected proportions of long-term sick leave due to respiratory disease.

The data were also analyzed by multiple logistic regression. The proportion of sick leaves due to a respiratory disease was higher among the women (OR 1.16) and older subjects (OR 1.013 per year). Industrial workers,

Table 4. Multiple logistic regression modela with gender, age, and occupation as independent variables. (OR $=$ odds ratio, $95 \% \mathrm{Cl}=$ $95 \%$ confidence interval)

\begin{tabular}{lcc}
\hline Independent variable & \multicolumn{2}{c}{ Dependent variable } \\
\cline { 2 - 3 } & $\mathrm{OR}$ & $95 \% \mathrm{Cl}$ \\
\hline Gender (male) & 0.80 & $0.80-0.88$ \\
Age at start of sick leave (year) & 1.013 & $1.012-1.015$ \\
Occupation & & \\
Industrial workers & 1.28 & $1.20-1.37$ \\
Graphic printers & 1.20 & $1.08-1.32$ \\
Agricultural workers & 1.20 & $0.98-1.45$ \\
Wood workers & 1.16 & $1.07-1.26$ \\
Food industry workers & 1.13 & $1.04-1.23$ \\
Metal workers & 1.12 & $1.07-1.17$ \\
Papermill workers & 1.03 & $0.92-1.15$ \\
Commercial workers & 0.99 & $0.93-1.06$ \\
Transportation workers & 0.98 & $0.89-1.08$ \\
Electricians & 0.96 & $0.80-1.14$ \\
Forestry workers & 0.92 & $0.74-1.15$ \\
Caretakers & 0.88 & $0.79-0.97$ \\
Painters & 0.85 & $0.69-1.05$ \\
Construction workers & 0.75 & $0.69-0.82$ \\
Hotel \& restaurant workers & 0.75 & $0.65-0.86$ \\
Hets
\end{tabular}

a All sickleaves included ( $N=210755$ ).

b Sick leave due to respiratory disorder $4.4 \%$.

Table 5. Multiple logistic regression modela with gender, age, and occupation as independent variables. (OR = odds ratio, $95 \%$ $\mathrm{Cl}=95 \%$ confidence interval)

\begin{tabular}{|c|c|c|}
\hline \multirow[t]{2}{*}{ Independent variable } & \multicolumn{2}{|c|}{ Dependent variableb } \\
\hline & OR & $95 \% \mathrm{Cl}$ \\
\hline Gender (male) & 0.98 & $0.89-1.07$ \\
\hline Age at start of sick leave (year) & 1.022 & $1.018-1.026$ \\
\hline \multicolumn{3}{|c|}{ Occupation } \\
\hline Agricultural workers & 1.52 & $1.10-2.10$ \\
\hline Industrial workers & 1.28 & $1.12-1.46$ \\
\hline Food industry workers & 1.20 & $1.01-1.41$ \\
\hline Painters & 1.15 & $0.84-1.58$ \\
\hline Graphic printers & 1.13 & $0.93-1.38$ \\
\hline Papermill workers & 1.10 & $0.87-1.37$ \\
\hline Wood workers & 1.05 & $0.89-1.24$ \\
\hline Transportation workers & 1.02 & $0.86-1.20$ \\
\hline Commercial workers & 1.01 & $0.88-1.15$ \\
\hline Metal workers & 0.98 & $0.89-1.07$ \\
\hline Forestry workers & 0.87 & $0.60-1.26$ \\
\hline Caretakers & 0.80 & $0.66-0.97$ \\
\hline Electricians & 0.76 & $0.52-1.09$ \\
\hline Construction workers & 0.75 & $0.64-0.88$ \\
\hline Hotel \& restaurant workers & 0.73 & $0.57-0.93$ \\
\hline
\end{tabular}

a All sick leaves of $\geq 90$ days included ( $N=79426)$.

b Sick leave due to respiratory disorder $2.9 \%$, 
persons employed in graphic printing, woodworkers, and food industry workers had higher odds ratios for sick leave due to a respiratory disease than did metal workers (table 4).

Finally, among those with long-term sick leave, the proportion of respiratory sick leave (compared with other causes) was strongly associated with age but not with gender. Agricultural workers, industrial workers, and food industry workers had higher odds ratios for longterm respiratory sick leave than did metal workers. Caretakers, construction workers, and persons employed in hotel, and restaurants had lower odds ratios for long-term respiratory sick leave than did metal workers (table 5).

\section{Discussion}

The national Swedish AGS register offers a novel opportunity to study sick leave in relation to occupation. No large-scale population-based study on sick leave due to respiratory disease has previously been reported because data are not readily accessible. The AGS material is, however, extensive, and, in the present study, 211000 sick leaves were included in the analyses. Over $90 \%$ of the diagnoses on the issued certificates were, in retrospect, considered correct in a sample. Hence the internal validity of the material must be considered good.

Most of the registered airway diagnoses in the AGS register reflected symptoms related to respiratory infections. Persons without any concurrent airway disease are rarely on sick leave for longer than 14 days due to respiratory infections (6). Thus sick leaves lasting longer than 14 days due to a respiratory disease could indicate significant respiratory disease, such as asthma and COPD, and serve as a signal that preventive measures should be considered. Long-term sick leave ( $\geq 90$ days), irrespective of cause, is costly and associated with an increased risk for early retirement (7). We focused on long-term sick leave because of the serious consequences associated with it.

The study base comprised persons employed in manual and service occupations in the private sector during a 3-year period. The exact number of workers covered by this national insurance is not known. However, when data from the National Census Bureau and the various labor unions are combined, a fair estimate can be made.

An increase in the incidence of sick leave due to respiratory disease does not necessarily indicate an increased risk for disease due to exposure to agents in the workplace. In some occupations with decreasing job opportunities, there may be an increased tendency for early retirement, preceded by long-term sick leaves for all types of diseases. Such a tendency was also noted in the present study, in which there was a correlation between the incidence of long-term respiratory disease and the incidence of long-term disease with other diagnoses (figure 1a). This finding could have been due to true increases in both long-term respiratory disease and other long-term diseases due to workplace factors, but also due to decreasing job opportunities in the occupation.

Any uncertainty in the estimates of incidence was removed when data on proportions were analyzed. In addition, when comparisons were made between occupations with respect to the proportions of sick leave due to respiratory disease out of all other diseases, instead of using the incidence of respiratory disease, some of the social factors influencing the tendency to accept sick leave, regardless of disease, were canceled. The study of proportions, however, introduces another difficulty in that the proportion of sick leaves due to respiratory disease is influenced by changes in the incidence of other diseases, such as musculoskeletal disorders. This effect was also observed in the present study (figure 1b) and was partly compensated for by the study of outliers in such a relationship.

The proportion of long-term, as compared with shortterm, respiratory disease varied between occupations. Agricultural workers and painters, for example, showed a relative increase in the proportion of long-term respiratory disease (figure 1c). This finding may suggest that, in some occupations, sick leave due to short-term disease is difficult to implement in view of the particular work situation, and, when the disease is severe, a longterm sick leave is required.

Painters and agricultural workers who develop respiratory problems tended to have long sick leaves and may subsequently have had to find other types of occupations or retire. Thus sick leave seems to be influenced by several factors, such as pressure to stay on the job even if sick or to quit work because of underemployment or unhealthy exposure.

The magnitude of the impact of some occupations on long-term sick leave due to respiratory disease was considerable. Among agricultural workers there was a $50 \%$ risk for a long-term respiratory diagnosis in comparison with that of metal workers, after adjustment for differences in gender and age among those on sick leave. This result was not due to smoking, since agricultural workers have a lower prevalence of smokers and ex-smokers than metal workers do (L Nathell, $\AA$ Nygren, unpublished data). According to our data these differences between occupations were not due to lower proportions of musculoskeletal disease, which would have increased the proportion of respiratory disease. Agricultural workers had a relatively high proportion of long-term musculoskeletal disease (figure $1 b$ ). Metal workers were selected as a reference category in the logistic regression procedure since they constituted the largest group. Even metal workers ran a clearly higher risk of long-term 
respiratory disease than did some other low-risk occupations.

A difference in the age distribution of workers in different occupations is a possible confounding factor when the incidence of sick leaves between occupations is compared. In the present study the age distribution differed between occupations. And, for example, painters, food industry workers, and agricultural workers had lower median ages than the reference category, metal workers. However, there was no significant correlation between the age parameters and the incidences of sick leave for respiratory (or nonrespiratory) diseases. This finding sug gests that the effects of the age differences between occupations were small when compared with the effects of differences in other determinants of sick leave between occupations. In the study of proportions of respiratory to other diseases, the differences in age between occupations were largely canceled. There was also a relatively good correlation between the estimated incidence and the proportion of respiratory disease $(r=0.72$ for all lengths of sick leave and $r=0.56$ for long-term sick leave); this finding suggests that the results were not strongly confounded by age differences.

Although agricultural workers had a higher proportion of long-term sick leaves for respiratory disease than they did for other diseases, this difference was not clearly reflected in the crude estimated incidence data for long-term respiratory disease. The validity of the incidence data can be questioned, but, even if these figures are entirely correct, incidence data on sick leave also reflect life-style and the selection of workers into and out of a profession. It is, for instance, possible that the pressure to stay on the job even in the presence of sickness may be particularly high among agricultural workers. Market and selection factors may therefore be important in determining the overall risk for sick leave in various occupations, which was shown by the high correlation $(r=0.80)$ between the incidence of long-term sick leave due to respiratory disease and that due to nonrespiratory disease. Hence, analyses of proportions give valuable additional information on the impact of occupation on sick leave. However, the high correlation between the estimated incidence and the proportion of respiratory disease suggests that both measurements are useful.

Workers in agriculture are at increased risk for contracting respiratory diseases. The most likely reason is exposure to organic dust with direct effects on the airways, as well as sensitizing effects on the airways (89). According to a large European study on occupational asthma farmers, painters, plastic workers, cleaners, spray painters, and agricultural workers have high risks for asthma (10). Persons employed as spray painters, plastic processors and manufacturers, chemical processors, bakers, and laboratory workers have the highest risks for occupational asthma in the United Kingdom, according to the SWORD project (11). In Sweden, the highest rates of self-reported asthma are found among male bakers, furnacemen, male welders, female chemical and plastics production workers, and female poultry and dairy farm workers (12). The higher risks for long-term respiratory disease found for some occupations in our present study could therefore, in part, be due to work-related asthma.

Women had relatively more respiratory sick leaves than men, while men had more long-term respiratory sick leaves. This difference may have been due to behavioral differences between the genders. Men and women have different coping strategies with long-term intractable neck, shoulder, and back pain (14). Men and women with respiratory problems may also use different coping strategies, which are then reflected in their sick-leave patterns. Smoking habits could also account for the gender differences in the present study. Except for persons 45 years of age and younger, a greater proportion of men than women is comprised of smokers or ex-smokers (15). Men are therefore more prone to develop chronic bronchitis and other smoke-related airway diseases, such as COPD, that result in longer sick-leave periods.

In conclusion, this Swedish register study shows that the type of occupation has a major impact on the risk of long-term sick leave due to respiratory disease. Agricultural workers, industrial workers, food industry workers, and painters are particularly at risk.

\section{Acknowledgments}

Financial support for this study was received from the research department of the AMF insurance company and is hereby gratefully acknowledged.

We thank Anders Hägg, statistician, FOLKSAM, Stockholm, for the computer processing of the data. We also thank Professor Åke E Andersson, former director of the Institute for Future Studies in Stockholm, for his valuable advice and support.

\section{References}

1. Venables KM. Epidemiology. In: Parkes WR, editor. Occupational lung disorders. Oxford (England): Butterworth-Heinemann, 1995:209-21.

2. Ross DJ, Keynes HL, McDonald JC. SWORD '97: surveillance of work-related and occupational respiratory disease in the UK. Occup Med (Oxford) 1998;48(8):481-5.

3. Matte TD, Hoffman RE, Rosenman KD, Stanbury M. Surveillance of occupational asthma under the SENSOR model. Chest $1990 ; 5 \mathrm{~S}: 173-8$.

4. The National Board of Occupational Safety and Health, Statistics Sweden. Arbetssjukdomar och arbetsolyckor 1995 [Work-related disorders and injuries in 1995]. Stockholm: 
The National Board of Occupational Safety and Health, Statistics Sweden, 1997.

5. Keskinen H, Alanko K, Saarinen L. Occupational asthma in Finland. Clin Allergy 1978;8(6):569-79.

6. Karlsson $\mathrm{H}$, Klingstedt $\mathrm{M}$, Rylander $\mathrm{O}$. Utvecklingen av den ersatta ohälsan 1985-1996 [Trends in sick leave during 1985-96]. In: Marklund S, editor. Risk- \& friskfactorer [Risk and health factors]. Stockholm: Riksförsäkringsverket, 1997:7-29.

7. Lidwall U. Friskskrivning,förtidspensionering och sammansatta riskfaktorer [Recovering from sick leave, early retirement pension, and compound risk factors]. In: Marklund $\mathrm{S}$, editor. Risk- \& friskfaktorer [Risk and health factors]. Stockholm: Riksförsäkringsverket, 1999:43-60.

8. Schenker MB, Christiani DC, Cormier Y, Dimich-Ward H, Doekes G, Dosman J, et al. Respiratory health hazards in agriculture. Am J Respir Crit Care Med 1998;158(5 Pt 2):S1S76.

9. Vohlonen I, Terho EO, Horsmanheimo M, Heinonen OP,
Husman K. Prevalence of chronic bronchitis in farmers according to smoking and atopic skin sensitization. Eur J Respir Dis Suppl 1987; 152:175-180.

10. Kogevinas M, Anto JM, Sunyer J, Tobias A, Kromhout H, Burney P. Occupational asthma in Europe and other industrialised areas: a population-based study. Lancet 1999; 353(9166):1750_4.

11. Meredith SK, McDonald JC. Work-related respiratory disease in the United Kingdom, 1989-1992: report on the SWORD project. Occup Med 1994;44(4):183-9.

12. Toren K. Self-reported rate of occupational asthma in Sweden 1990-92. Occup Environ Med 1996;53(11):757-61.

13. Jensen I, Nygren A, Gamberale F, Goldie I, Westerholm P. Coping with long-term musculoskeletal pain and its consequences: is gender a factor? Pain 1994;57(2):167-72.

14. Statistics Sweden. Statistiska Centralbyrån. Stockholm: Statistics Sweden, 1995

Received for publication: 03 December 1999 